\title{
Reflecting on a survey of a municipality website using practitioner-based inquiry
}

\author{
Udo Richard Averweg* \\ Information Management Unit, eThekwini Municipality, P O Box 828, Durban, 4000, South Africa
}

\section{(C)2017 ACCENTS}

\begin{abstract}
Local government websites in South Africa are evolving unlocking their potential for serving their citizenry and as a catalyst towards service delivery of electronic government services. Usability testing is an invaluable tool for evaluating interfaces. In this review article, a discussion is made of a recent usability pilot survey for a selected local government website (eThekwini Municipality's website at www.durban.gov.za) and from an information systems (IS) practitioner based inquiry perspective, discusses this exploratory research. Inquiry that is practice-based is an essential tool for an IS practitioner when undertaking research in his workplace environment. This generates 'practical' and meaningful practitioner based knowledge for the organisation. When reflecting on a survey of a municipality website, the article concludes that knowledge has become an integral part of the professional IS practitioner's research strategies through active involvement in the generation of knowledge.
\end{abstract}

\section{Keywords}

Information systems practitioner, Practitioner-based research inquiry, Reflective practitioner, Website usability research.

\section{Introduction}

Local government websites in South Africa are evolving unlocking their potential for serving their citizenry and as a catalyst towards service delivery of electronic government services. Although these websites are intended to facilitate the process of information access to local government information, the quantum amount of information available on these websites can 'bewilder' the citizenry of users. There is therefore a fundamental requirement for gauging the usability of local government websites for their intended citizens. Usability testing is an invaluable tool for evaluating interfaces. Usability is a quality attribute that assesses how easy user interfaces are to use [1]. Usability testing thereby serves as an integral part of a website's future development and evolution. In this review article, a discussion is made of a recent usability pilot survey for a selected local government website (eThekwini Municipality's website at www.durban.gov.za) and from an information systems (IS) practitioner-based inquiry perspective, discusses this exploratory research report. There are numerous scholarly journals dealing with usability testing and these research outputs appear to be geared towards IS academic scholars.

*Author for correspondence

130
This results in professional IS practitioners (like the author) feeling sometimes alienated. IS practitioners often have problems finding relevant (and sometimes it is claimed, difficult to read) academic research literature which has no practical relevance. It appears that over time as the IS field has developed, the world of IS practitioners has distanced itself from that of IS academic researchers and so the potential for disconnection (or chasm) has arisen. While there may be argument for this viewpoint, research methods exist for IS practitioners to 'connect' to the double hurdle of practical relevance and theoretical and methodological rigour [2]. Practitioners are also in a better position to identify relevant problems which have real organisational impact [3]. Practitionerbased inquiry research may therefore be seen as a bridge to span the chasm between IS practitioners and IS scholars. For the purposes of this review article the author, as a professional IS practitioner, has taken a practitioner-based inquiry research perspective for the usability testing survey of eThekwini Municipality's website. He has the time to carry out this research [4].

eThekwini Municipality is a metropolitan municipality in South Africa. The importance of usability testing and the applicability of usability testing to local government websites cannot be understated. 


\subsection{Objectives}

A practitioner is a professionally employed person who is gainfully employed in a selected discipline (such as IS) and is concurrently carrying out a systematic inquiry relevant to his job [5]. Practitioner research is seen as research that is done by practitioners to advance their practice. The professional practitioner should be able to demonstrate a combination of practical IS work and engage in workplace specific research. He should be able to critically reflect on his practice - this is a development of Donald Schön's [6] notion of the reflective practitioner. The reflective practitioner is therefore someone who is simply thoughtful about his practice and such practice forms an integral part of the IS discipline [7].

While engaging IS practitioners in research is not easy, doing so can enhance IS scholarship by bringing IS practitioners' perspectives, local knowledge and theories to bear on the cumulative knowledge of the IS discipline. It improves the technical and general knowledge skills of the IS practitioner and also elevates the professional status of practitioners engaged in the IS discipline.

The objectives for this review article are twofold:

- To demonstrate that practitioner-based inquiry can (and does) bring acceptable scholarly research directly into the hands of IS practitioners; and

- To underscore that, generally-speaking, IS practitioners' involvement in research and general inquiry that is small-scale, local, grounded and carried out by such professional practitioners who directly deliver IS services, is an essential ingredient of good practice in the business world and management workplace environment. Such workplace environment includes local governments in South Africa.

\section{Background to research work}

In the IS discipline there is a plethora of IS research that has been carried out and published in journals, textbooks, trade magazines, etc. In the case of IS research published in refereed journals and other reputable journals, very often empirical research methodology approaches have been used by the researcher(s). However, it is increasingly accepted in IS that empirical research is not the only valid scientific methodology that could be used to produce good research. For example, the 'father' of IS research in South Africa, the (late) Professor Dewald Roode has criticised IS researchers for being too positive-minded in their leanings, and for being unaware of an array of methodological choices [8].

Practitioner-based inquiry research may therefore be another methodology that could introduce a 'softer' view and use of information and information technology (IT) in local government organisations this may be more applicable than the 'harder' approaches that are typically found in the natural sciences (such as, for example, Physics). Practitionerbased inquiry research is found in the IS literature see, for example $[5,7,8]$.

Practitioner-research can be described as "a systematic form of enquiry that is collective, collaborative, self-reflective, critical and undertaken by the participants of the inquiry" [9]. Practitioner-based researchers very often apply exemplars and theories to their own experiences and situations in their jobs in organisational settings while maintaining strong ethical principles. Practice must usually be accompanied by documentation of the research process, some form of explanation or textual analysis, and a demonstration of critical reflection by the IS practitioner [7].

Practitioner-based inquiry research suggests an open view to any appropriate methodology which may inform the professional IS practitioner in the workplace in an organisation. It is evident that when selecting the appropriate methodology for conducting practitioner-based inquiry research, the professional IS practitioner will require skills based on his theoretical IS and IT knowledge. This in turn should 'grow' the professional IS practitioner's practical IS and IT work skills in organisations. Such work skills can have direct and indirect business benefits to, for example, eThekwini Municipality.

Research is to be understood as original investigation undertaken by the IS practitioner in order to gain knowledge and understanding which is of direct relevance to the needs of organisations (such as eThekwini Municipality) and where these lead to new or substantively improved insights. "Unfortunately, much of the research published in academic business journals is often seen as being too theoretical and of little practical relevance to business professionals" [10]. One practical approach to mitigate this possible limitation, is to craft and submit a review article to, for example, the editorial team of the International Journal of Advanced Technology and Engineering Exploration. Following possible refinement processes, an (accepted) reviewed article may then 
have the potential of publication by the ACCENTS publisher. The published review article, by a professional IS practitioner, then enjoys suitable prominence in an IS scholarly publication. Baskerville and Myers [11], in a MIS Quarterly article, suggest that "reflections on current [IS] practice could be given more prominence in IS scholarly journals".

Active participation by IS practitioners in the IS research realm in organisational domains is a required necessity but also demands an analysis of the actual context within which IS practices function. Despite the 'disconnection' between IS practitioners and IS scholars, IS practitioner-based inquiry leaves untouched an activity that is central to the development of the IS field: the production of knowledge through research. Practitioner-based inquiry brings acceptable scholarly research directly into the (practical) hands of IS practitioners. After a definition of the research problem, all research commences with an explicitly defined research question.

\section{Research methodology}

Many researchers use data from available data and archives either in the form of documents or survey results for secondary analysis [12]). Secondary analysis is the analysis of a document or data gathered or authored by another person or organisation (eg. Creative Lead). Hyman (cited in [12]) lists one of the benefits of secondary analysis as a savings of time. One of the disadvantages of secondary analysis is that the original data may contain errors that the secondary researcher may not be able to detect. The author is particularly mindful thereof. Secondary data and analysis are used for the purposes of this article in facilitating the author's own reflectivity.

Research on corporate websites, as tools of online communication, in accordance with how they apply usability to the content they present, can be found in the literature - see, for example, [13]. The data for eThekwini Municipality's website usability was recently collected by an independent company, Creative Lead. The author participated in the survey via an 'onsite session' with a representative from Creative Lead. The report entitled REPORT: Pilot eThekwini Website Usability Analysis \& Improvement Strategy was made available to the communications department,

eThekwini Municipality. The author was given an electronic copy. The rationale for using this secondary data for this article is that (1) it is considered relevant to practitioner-based inquiry; and (2) there are potential savings of time and money by using this 'available' data rather than collecting original data.

From the REPORT: Pilot eThekwini Website Usability Analysis \& Improvement Strategy, the reported findings (from the quantitative data) will serve to inform the author's practitioner-based inquiry. After defining the research problem, the starting point for such inquiry will be the formulation of the research question. It should be expressly noted that it is not the intention by the author to criticise the compiled report but rather to use it towards further developing the author's practitioner IS skills set so that he can make a meaningful contribution to the practice of IS practitioner-based inquiry research. The author's reported findings are based upon the methodology applied to gather the information. The findings of the research are arranged in a logical sequence without bias.

In [14] suggest that all "researchers should ask themselves whether their research is designed to give valid and believable conclusions"- it is contended that by using the pilot study results, it will aid the process of practitioner-based inquiry research. It is felt that with practitioner-based research, we can all benefit from 'connected' academic discourse and practitioner reflections in the IS field.

There is a genuine need to explore the real-life phenomenon of the usability of local government websites in South Africa. During such inquiry, the professional IS practitioner must be mindful that practitioner research should be self-reflective and critical. Ethical research practices must also be subscribed to.

\section{Survey results and findings}

A research question is a question that can be answered directly through the appropriate analysis of collated data. A research question must be sufficiently specific so that survey questions can be created to answer the stated question.

Extracted from page 7 of the REPORT: Pilot eThekwini Website Usability Analysis \& Improvement Strategy by Creative Lead is the following text:

"The onsite sessions were individually less than three minutes. During the sessions, the [Creative Lead] team explained the session and asked the participant 
to fill out a brief background questionnaire. The test scenario was based on the participant's interaction (sic) with the municipality. Then participants were asked to try and find the information on the website. After the task was completed, the test administrator asked the participant to rate the website overall by using a 5-point Likert scale (Strongly Disagree to
Strongly Agree) for six subjective measures on our online survey.

Extracted from page 10 of the report is the summary of the results of the online survey-see Table 1:

Table 1 Summary of results of online survey

\begin{tabular}{|c|c|c|c|c|c|}
\hline & $\begin{array}{l}\text { Strongly } \\
\text { disagree }\end{array}$ & Disagree & Neutral & Agree & Strongly agree \\
\hline $\begin{array}{l}\text { It is easy to navigate through this } \\
\text { website }\end{array}$ & 7 & 22 & 37 & 76 & 33 \\
\hline $\begin{array}{l}\text { It is easy to find what you want on } \\
\text { this website }\end{array}$ & 6 & 57 & 46 & 66 & 12 \\
\hline This website loads too slowly & 21 & 44 & 49 & 49 & 23 \\
\hline $\begin{array}{l}\text { The graphics on this web site are } \\
\text { pleasing }\end{array}$ & 13 & 22 & 50 & 81 & 21 \\
\hline $\begin{array}{l}\text { Clicking on the links takes me to } \\
\text { what I expect }\end{array}$ & 11 & 43 & 40 & 69 & 23 \\
\hline \multirow{2}{*}{$\begin{array}{l}\text { The organization of information on } \\
\text { the website screen is clear }\end{array}$} & 9 & 40 & 36 & 85 & 17 \\
\hline & 67 & 228 & 258 & 426 & 129 \\
\hline
\end{tabular}

(Source: REPORT: Pilot eThekwini Website Usability Analysis \& Improvement Strategy: p.10)

The report contains and on page 10 , the following is stated:

"After the task session completion, participants rated the site for overall measures. There is always a larger number that the website is easy to navigate, easy to find what you want online, does load slowly, the graphics are pleasing... But there is a disturbing large number of uses (sic) that are either neutral or disagree with the points raised. The overwhelming majority, agrees only that the website loads at a fair speed".

When one critically reflects on these survey results (in the above table) and the comments made (on page 10), the question arises whether they are contextually meaningful. Do the survey results have relevance for eThekwini Municipality's website usability? The answer thereto lies with the research question. Since the research question had not been explicitly defined, there is a disjuncture between the objectives of the research and analysis of data and the reported findings. In scholarly academic discourse this is a significant research flaw. In scholarly IS research, such reported data analysis and findings would simply have been discarded.

For IS practitioner-based inquiry (and when one critically reflects thereon) such 'loose' findings can nevertheless serve as both practical relevance and as a useful insight tool when designing practitionerbased inquiry research. Being self-reflective assists a professional IS practitioner in defining the intended research question. By doing so, the IS practitioner based inquiry research to be conducted is then rooted in the actual context within the IS practice functions in the selected organisation (for example, eThekwini Municipality). The analysis of data and resultant findings from such practitioner based inquiry research then creates 'practical' and meaningful practitioner based knowledge for the organisation. The reported findings are both valid and a believable conclusion to such inquiry research.

Such arching practitioner-based inquiry approaches, may result in IS practitioners turning to IS scholars to develop strategies and practices for their respective workplace environments. IS scholars may also turn to IS practitioners to frame their research questions and/or to reflect and interpret their research results. This will serve as a meaningful stepping stone to bridge the chasm (or 'disconnect') between IS practitioners and IS scholars.

\subsection{Business benefits}

The production and creation of 'new' knowledge is not simply IS theory applied to IS practice - it is a different kind of knowledge [7]. Significantly, it is produced by reworking IS theory into IS practice. It would seem that only via the IS practitioner-based inquiry research method and through the process of reworking IS theory can such new (and different kind of) knowledge, that is so prized, be produced by the IS practitioner. However, further investigation 
thereof is an avenue for future research. An IS practitioner should also critically reflect on how such 'new' knowledge was created.

For the IS practitioner who conducts practitioner-based inquiry in the IS discipline in his workplace environment (such as local government, eThekwini Municipality), the business benefits may be anchored on the following hexagon:

- He spans the chasm between the IS practitioner and the IS scholar;

- He elevates the professional status of IS practitioners in the IS discipline;

- He has strong ethical principles, demonstrates relevant, up-to-date skills and capabilities appropriate to a particular role with practical experience complementing theoretical knowledge;

- He is thoughtful about 'his' IS practice and such practice forms an integral part of the IS discipline;

- He creates 'new' knowledge which is not simply IS theory applied to IS practice;

- He also critically reflects thereon.

\section{Conclusion and future work}

Inquiry that is practice-based is therefore an essential tool for the professional IS practitioner when undertaking research and review in his workplace environment. Review and the practice of reviewing forms part of the IS practitioner's knowledge creation. Knowledge becomes an integral part of the IS practitioner's professional research strategies through active involvement in the generation of knowledge that is based on practice when designing and implementing IT solutions. Such IT solutions include websites. Professional knowledge creation is knowledge which is derived from the systematic accumulation of evidence in the IS practitioner's workplace environment.

Local government websites have become an integrated part mainstream daily life in South Africa. Whilst developing a usable and effective website is challenging, maintaining and redesigning a website to meet the constantly changing needs of its citizenry, may be a seemingly impossible task. Future usability surveys are therefore ideally geared to this undertaking since they not only assist in identifying interface problems, but also produce practical knowledge through research.
This knowledge then assists in developing ways in which to address and remedy those identified problems. After all, the results from a usability survey of a website from practitioner-based inquiry, should serve as a catalyst towards improving the service delivery of electronic government services in South Africa.

\section{Acknowledgment}

None.

\section{Conflicts of interest}

The author has no conflicts of interest to declare.

\section{References}

[1] Nielsen J. Usability 101: Introduction to usability. https://www.nngroup.com/articles/usability-101introduction-to-usability/ Accessed 14 September 2017.

[2] Pettigrew AM. Management research after modernism. British Journal of Management. 2001; 12(S1):S61-S70.

[3] Nagle T, Sammon D, Doyle C. Meeting in the middle: bridging the practice research divide from both sides. In ECIS 2016 (p. ResearchPaper158).

[4] Gordon SP. Expanding our horizons: alternative approaches to practitioner research. Journal of Practitioner Research. 2016; 1(1):2.

[5] Robson, C. Real world research: A resource for social scientists and practitioner-researchers. Oxford, UK: Blackwell Publishers 2002.

[6] Wilkinson J. Implementing reflective practice. Nursing Standard. 1999; 13(21):36-40.

[7] Averweg UR. Information systems: practitioner-based inquiry research. IT Professional. 2013; 15(3):44-7.

[8] Roode D. Information systems research: a matter of choice? South African Computer Journal. 2003; 2003(30):1-2.

[9] McCutcheon G, Jung B. Alternative perspectives on action research. Theory into practice. 1990; 29(3):14451.

[10] Myers MD. Qualitative research in business and management. Sage; 2013.

[11] Baskerville RL, Myers MD. Fashion waves in information systems research and practice. Mis Quarterly. 2009:647-62.

[12] Bailey K. Methods of social research. Simon and Schuster; 2008.

[13] García García M, García García M, Carrillo-Durán MV, Carrillo-Durán MV, Tato Jimenez JL, Tato Jimenez JL. Online corporate communications: website usability and content. Journal of Communication Management. 2017; 21(2):140-54.

[14] Blanche MT, Blanche MJ, Durrheim K, Painter D, editors. Research in practice: applied methods for the social sciences. Juta and Company Ltd; 2006. 


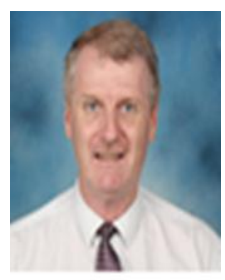

Udo Richard Franz Averweg is employed as an Information Technology (IT) Project Manager at eThekwini Municipality, Durban, South Africa. He entered the IT industry during 1979 and holds a Masters Technology degree in Information Technology (cum laude), a second Master's degree in Science from the University of Natal and a third Master's degree in commerce from the University of KwaZulu-Natal, Durban, South Africa. As an IT practitioner, he is a registered professional member of the Institute of Information Technology Professionals, South Africa. He has authored and co-authored more than 180 research outputs ( 80 being peer-reviewed): some research outputs have been delivered at local conferences, some have been published in accredited peer-reviewed journals and some have appeared as chapters in books. In 2012 he published a book entitled Decision-making support systems: Theory and practice. During January 2000 Udo climbed to the summit of Africa's highest peak, Mount Kilimanjaro (5,895 metres), in Tanzania.

Email:udo.averweg@durban.gov.za 